\title{
Study on Slope treatment and Greening construction technology of Road Engineering
}

\author{
Zhengwei Feng ${ }^{1}$, Longbin Lin ${ }^{1, *}$ \\ ${ }^{1}$ Department of Engineering Management, Xiamen University Tan Kah Kee College, \\ Zhangzhou, Fujian Province, 363105, China
}

\begin{abstract}
Slope greening is an important part of road engineering construction. Its main purpose is to improve the ecological environment on the side of the road and improve its ability to resist geological disasters. The engineering features of this paper are long road engineering, large area of slope treatment. It analyzes the technical difficulties in the construction of slope greening project, such as large excavation depth, more stone slopes along the road, serious exfoliation of external soil and less nutrients in the soil.In view of the above technical difficulties, the key construction techniques such as excavation and filling slope construction, external soil direct seeding, spray seeding of external soil with hanging net, slope maintenance, combination of skeleton protection and plant slope protection are studied. It ensured the quality of the project and provided reference for the construction of related projects.
\end{abstract}

\section{Project overview}

With the rapid development of highway projects in mountainous areas, the slope greening can not only improve the stability of the slope, but also restore vegetation and achieve environmental protection. Through reasonable planning and planting of vegetation, it can promote the growth of other plants and soil microorganisms, form a mature ecosystem, and maintain the diversity of ecological environment. The application of slope greening technology can give full play to the photosynthesis of vegetation and thus play the role of air purification and vegetation consolidation, reduce the impact of rainfall, improve soil permeability, reduce surface runoff, and improve the stability of the slope [12].

The north section of Banshan road is located in Zhangzhou Development Zone of China Merchants Group. It is divided into two phases, this project is the first phase, mainly includes slope protection, drainage, temporary road, landscape greening, greening and irrigation works. The total length of the temporary road is about $2.67 \mathrm{~km}$.

Slope protection project introduction: No.1 slope is located in the west side of Nanbin Avenue, facing Xiamen Bay in the north, and transportation is very convenient. The proposed BanShan road is used as the platform of the slope. The slope is six steps high, with a maximum height of $56.02 \mathrm{~m}$. The height of first step is $6 \mathrm{~m}$, the rest are $10 \mathrm{~m}$, and the width of design platform is $4 \mathrm{~m}$. The slope is mainly composed of Yanshanian granite weathering layer, and there are boulders on the top of the slope. No. 2 slope have 6 steps, the height is $51.57 \mathrm{~m}$, the step is height of $10 \mathrm{~m}$ and platform width of $4 \mathrm{~m}$.
The slope treatment area is large, it mainly include flexible protective net and some stone slopes, rock soil mixed slopes, arch skeleton slope protection, frame beam slope protection, geotechnical network slope protection and slope of spoil ground. According to the topography and characteristics of the project area, the soil conditions on the site are analyzed, and the current mature vegetation restoration technology is adopted. It is intended that after the completion of the project, the current bare slope can be effectively improved, the treatment degree reaching will be over $98 \%$, the sediment output reducing will be over $95 \%$, the forest and grass vegetation coverage will be over $85 \%$, and the survival rate of arbor and shrub will be over $80 \%$, so as to create a new image of Zhangzhou Development Zone.

\section{Construction difficulties of slope greening engineering}

The main construction difficulties of slope greening in this project are as follows:

First, the project is located in the mountainous area, with a large area of slope, include 8 slopes with excavation depth of more than $10 \mathrm{~m}$, and the angle of the slope is large, which it affects the attachment effect of green plants in the soil.

Second, there are stone slopes along the road, and the soil structure is mostly exposed rock, so this kind of slope is seriously lack of enough water and soil for plant growth, especially in the rainy season, the normal growth of plants is seriously hindered by rain. In general, the technology of spraying and planting is adopted for stone slope, but it has the disadvantages of long construction

\footnotetext{
* Corresponding author: $1 \mathrm{lb@xujc.com}$
} 
period and long maintenance period. The ecological restoration technology of stone slope needs to be improved.

Third, the road slope is generally suitable for planting a certain number of shrubs to improve its landscape effect, but the nutrient in the slope soil is less, and have many herbaceous plants, which will undoubtedly have a negative impact on the normal growth of shrubs.

Fourth, after the trial spraying of the slope, there will be serious exfoliation of the soil, and thunderstorm will occur frequently in this area in summer, so the slope will be washed seriously.

\section{Key Technology of slope greening construction}

\subsection{Slope greening method}

\subsubsection{Excavation slope}

According to the different lithology characteristics and slope classification of the excavation slope, different greening methods are adopted.

- The first and second excavation slopes are generally protected by the method of spraying and seeding with the external soil, and the azalea, yellow allamanda and other flowers and shrubs are planted according to the slope conditions.

- Third level excavation slope: the first level slope is protected by hanging net spraying the external soil(spraying $6 \mathrm{~cm}$ thick), the second and third level slopes are generally protected by spraying external soil, and the first level slope is decorated with azalea, yellow allamanda and other flowers and shrubs.

- Excavation slope above grade IV (including grade IV): the first and second grade slopes are generally protected by hanging net spraying the external soil(spraying $6 \mathrm{~cm}$ thick); the slopes above third grade (including grade III) are generally protected by spraying with the external soil ( $3 \mathrm{~cm}$ thick), and the first level slope is decorated with azalea, yellow allamanda and other flowers and shrubs.

- The 10 rhododendrons and 10 cicadas will be planted every $100 \mathrm{~m}$ of the first slope. The planting mode is 3-7 plants in each cluster, and the spacing between each cluster is about $25 \mathrm{~m}$.

\subsubsection{Fill slope}

Taiwan turf shall be fully paved within the range of filling slope $1 \mathrm{~m}$ below the soil shoulder to resist the erosion of the slope caused by the initial rainwater runoff, the whole filling slope shall be protected by spraying and sowing of external-soil.

\subsection{Slope greening construction technology}

\subsubsection{External soil direct seeding}

The original construction technology of spray seeding and grass planting is improved and optimized. After the construction, when the seeds such as shrubs grow up, the life cycle of shrubs and the restoration of ecological environment are much better than that of herbs. The key of this construction technology is the selection of plant seeds.

- External soil direct seeding technology and slope maintenance:

The organic materials, soil, seeds, other additives and water are stirred evenly in proportion, and then sprayed onto the rock surface by construction machinery. After the plant growth organic layer was formed on the slope, it was covered with $12-13 \mathrm{~g} / \mathrm{m}^{2}$ spinning cloth [3]. It is very important to maintain seed germination and formation period after spraying. In the summer construction, the water and fertilizer management should be strengthened during the seed germination period. After about three months of normal growth, the number of watering can be gradually reduced and the adaptability of plants can be exercised. After half a year of maintenance, the coverage rate can reach $95 \%$.

- Plant seed ratio:

Herbs: dwarf bermuda, $5 \mathrm{~g} / \mathrm{m}^{2}$; Stylosanthes guianensis, $6 \mathrm{~g} / \mathrm{m}^{2}$; molasses grass, $4 \mathrm{~g} / \mathrm{m}^{2}$. Rattan: big winged bean, $5 \mathrm{~g} / \mathrm{m}^{2}$. Shrub: Leucaena leucocephala, $7 \mathrm{~g} / \mathrm{m}^{2}$; Wild beans, $5 \mathrm{~g} / \mathrm{m}^{2}$.

\subsubsection{Spray seeding with net mounted external soil}

The spray seeding with net mounted external-soil is a new type of spray seeding greening method. The specific method is to mix organic base material, long-term fertilizer, quick acting fertilizer, water retaining agent, adhesive, plant seeds, etc. according to a certain proportion, and then add water to mix them evenly, and finally spray them on the slope of the wire laying net with a special spraying and mixing machine. Due to the binding effect of the adhesive, the mixture can form a porous and stable structure (i.e, a layer of hardener with continuous gaps) on the surface of the slope, which can not only make the plants grow but also be uneasily washed out. The seeds can take root, germinate and grow in the gaps, so as to restore the vegetation, improve the landscape and protect the environment. In order to give consideration to the effect of short-term and rapid slope coverage and long-term vegetation restoration, the seeds of herbs, shrubs and even trees are selected for mixed seeding, and the seedlings of shrubs and vines are planted on the slope [4].

- Spraying and sowing technology of net mounted external-soil:

The construction sequence was as follows: slope cleaning $\rightarrow$ steel wire mesh laying and anchor fixing $\rightarrow$ spraying organic material base course $\rightarrow$ covering nonwoven fabric $\rightarrow$ maintenance. Slope trimming: Slope trimming: Ecological Renovation shall be carried out on 
the stable slope as required, and the construction slope shall be basically stable. The pumice on the slope shall be trimmed to meet the construction requirements.

Driving anchor bolts and hanging wire mesh: laying wire mesh on the slope surface for slope protection can prevent the slope surface from collapsing, enhance the slope protection ability, and play a role of "reinforcement" on the organic material layer. The wire mesh shall be machine-made wire mesh with the specification of $6.5 \times 6.5 \mathrm{~cm}$ and the wire diameter of $\Phi$ $0.22 \mathrm{~cm}$. The wire mesh shall be laid down along the slope surface, it shall be tightened and kept smooth with the slope surface during laying. Then, the drill shall be used to drill holes on the slope surface, and the wire shall be fixed with anchor bolts. The selection of anchor bolt is $\Phi 14 \mathrm{~mm}$, short anchor bolt is $25 \mathrm{~cm}$, long anchor bolt is $45 \mathrm{~cm}$, the density control principle of anchor bolt is one per square meter, and the long and short anchor bolts are alternately anchored [5].

The organic materials, soil, seeds, other additives and water are stirred evenly in proportion, and then sprayed onto the rock surface by construction machinery, the average thickness of construction spray is $6 \mathrm{~cm}$, it was covered with $12-13 \mathrm{~g} / \mathrm{m}^{2}$ spinning cloth.

- Slope maintenance:

The maintenance mode of the slope is basically the same as that of external-soil direct seeding technology. According to the weather conditions in the dry season, regular care should be carried out to make it enter the vigorous growth period smoothly. After one year's maintenance, the plant coverage rate can reach $95 \%$.

- Plant selection and configuration :

Slope vegetation restoration can't only rely on a single grass planting, because grass will wither and even die, it can't achieve the effect of natural vegetation restoration, so we must take the combination of irrigation, rattan and grass. The guarantee of early effect mainly depends on grass planting, and the later effect mainly depends on the growth of shrub and rattan plants. The principle of plant selection is to ensure the permanent treatment of the slope and meet certain landscape requirements [6].

\subsubsection{Skeleton protection and Plant slope protection}

The combination of skeleton protection and plant protection is adopted, as shown in Figure 1. First of all, the wedge-shaped ditch shall be excavated manually on the skeleton slope according to the certain row spacing, and the suitable organic fertile soil such as soil nutrients and soil amendments shall be filled in the ditch. Then it will hang a three-dimensional vegetation network, spray and plant grass, and plant shrubs to form a threedimensional comprehensive plant protection measures. Try to ensure that lines are no thinner than 0.25 point.

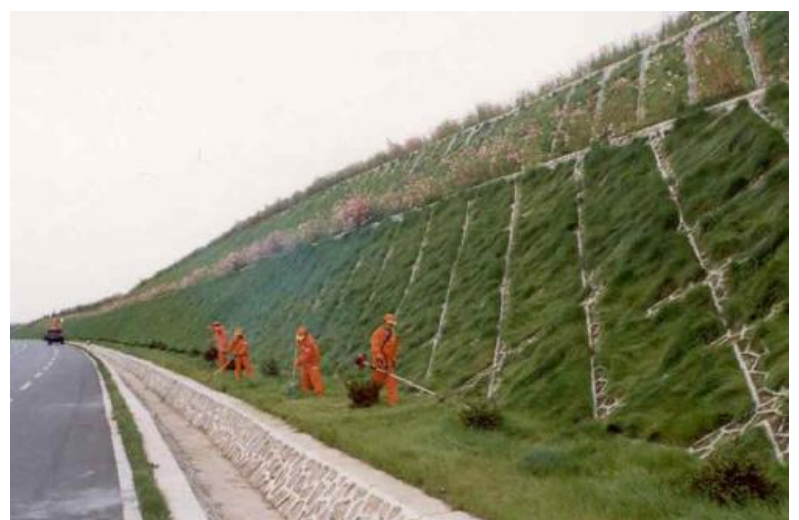

Fig. 1. Schematic diagram of combination of skeleton protection and plant protection

The specific construction technical points are as follows: - The slope surface shall be leveled to meet the design requirements, and the slope can be repaired manually.

- The hoe and other tools shall be used to excavate holes with a depth of $30 \mathrm{~cm}$ and a diameter of $15 \mathrm{~cm}$ on the slope surface, and the number of holes per square meter shall not be less than 8 .

- The hole is refilled with soil rich in organic fertilizer, and the shrub seeds are required to be sown after the filling is lightly tamped.

- There are no less than 3 kinds of shrub seeds per square meter.

- The slope surface shall be watered properly to ensure the humidity. When the height of the shrub reaches $5 \mathrm{~cm}$, the three-dimensional vegetation network shall be hung for spraying the grass hydraulically. After spraying and sowing, a small amount of fine soil can be spread to cover the vegetation network according to the situation.

- It finally covers the non-woven fabric and sprays water regularly to maintain the slope until the grass grows all over the terrace.

\section{Problems to be noticed in slope greening construction}

\subsection{External soil spraying and sowing project}

The following problems should be paid attention to in the project of spraying and sowing of external soil:

- The grass seeds used for spraying can adapt to the local climate conditions and spraying technology, and the seeds have good germination rate, and can grow and develop normally after germination.

- Before the spraying and sowing of the external soil, the slope shall be cleaned and the preparation for spraying and sowing shall be done well. According to the construction technical requirements, the raw materials with good quality are used to process organic base materials.

- The spraying and sowing work of the external soil shall be operated by experienced professional construction personnel and guided by full-time management personnel to ensure the project quality. 
-The real-time detection of various detection instruments is adopted to ensure the quality control in the construction.

- It is necessary to water, fertilize and control diseases and insect pests regularly to ensure the normal and healthy growth of plants.

\subsection{Rock slope hanging net and spraying external soil project}

The following problems should be paid attention to in the engineering of spraying and sowing external soil with hanging net on the rock slope:

- The construction shall be carried out based on the design drawings, and the wire mesh shall be hung to the specific person in charge.

- We should repair and maintain the defects in time. If the greening effect of the slope is affected due to objective reasons in the construction process, the defect repair work shall be carried out in time to ensure the quality of the project and the effect of the landscape.

During the construction of the project, there may be rainy and typhoon seasons. In the field construction, the weather factors have a relatively obvious impact on the construction. In order to ensure the smooth progress of the construction, it is necessary to formulate a detailed construction schedule and strictly follow the construction plan.

\section{Conclusion}

Slope greening engineering is an important part of road engineering construction. Its construction quality affects the use function of the road, so it should be given enough attention. In the construction of slope greening, we should not only select the best construction technology according to the actual situation of the project, but also pay attention to the selection of plant species in ecological slope protection. This project introduces the construction difficulties of slope greening, and puts forward the key construction technology methods, such as excavation and filling slope construction, external soil direct seeding, spray seeding of external soil with hanging net, slope maintenance, combination of skeleton protection and plant slope protection, etc.The engineering practice proves that the application of the construction technology is effective and can be popularized in similar projects.

\section{References}

1. L. Su. Practice of slope support and greening project of poly Lin $\mathrm{Yu}$ mountain villa in Guangzhou Science City [J]. Guangdong garden. 04, 37 (2013)

2. T. Mao. Application of spray seeding technology in afforestation project of high grade highway in Gansu Province $[\mathrm{J}]$. Beijing agriculture. 18, 42 (2013)
3. Z.R. Jia, W, Zhang. Study on evaluation index and method of vegetation restoration quality of highway slope $[\mathrm{J}]$. Bulletin of soil and water conservation. 01, 76 (2008)

4. S.B. Li. Analysis of highway slope greening technology $[\mathrm{J}]$. China high tech enterprise. 11, 39(2008)

5. Y.S. Hao, G.B. Wang, F.X. Wan. Construction and ecological evaluation of Expressway ecological slope in China [J]. Soil and water conservation research. 04, 102 (2007)

6. F.X.Dai, L.Song, T. Wang, B. Long. Slope greening technology and application $[\mathrm{J}]$. China soil and water conservation. 11, 133 (2009) 